\title{
Qualidade da água consumida por uma comunidade rural na região do Sertão Central, Ceará
}

A água é essencial para os seres humanos, no entanto, a sua disponibilidade vem se tornado cada vez mais difícil pelo o comprometimento da qualidade para fin de consumo devido à poluição causada por diferentes fontes, tais como: efluentes domésticos, efluentes industriais e deflúvio superficial urbano e agrícola. Nesse contexto, este trabalho objetivou avaliar os padrões de qualidade da água para consumo de fontes subterrâneas e superficiais no Distrito de Custódio no Município de Quixadá, Ceará. A pesquisa foi caracterizada como do tipo observacional, sendo também transversal e qualitativo-quantitativa, onde foram analisadas cinco fontes alternativas de abastecimento, sendo quatro poços e um açude. Os resultados foram comparados à portaria de consolidação vigente de $n$-5 de 2017 do Ministério da Saúde. Como resposta, verificaram que houve alterações físico-químicas para cor (20\%), turbidez (20\%), dureza total (20\%), cloretos (60\%) e amônia (80\%), como também $100 \%$ de contaminação microbiológica nas amostras coletadas, estando fora dos valores máximos permitidos pela portaria vigente, mostrando que as fontes de água estão inadequadas para consumo humano. Desse modo, as implementações de medidas urgentes necessitam serem efetivadas, além de melhorias no saneamento básico da região, a fim de reduzir ou eliminar contaminantes que possam estar presentes nas fontes.

Palavras-chave: Água potável; Doenças de veiculação hídrica; Saúde pública.

\section{Quality of water consumed by a rural community in the Central Hinterland, Ceará}

\begin{abstract}
Water is essential for human beings, however, its availability has become increasingly difficult due to the compromise of quality for consumption purposes due to pollution caused by different sources, such as domestic effluents, industrial effluents, and surface runoff urban and agricultural. In this context, this study aimed to evaluate the water quality standards for the consumption of underground and surface sources in the Custódio District in the Municipality of Quixadá, Ceará. The research was characterized as observational, also cross-sectional, and qualitative-quantitative, where five alternative sources of supply were analyzed, four wells and a weir. The results were compared to the Ministry of Health's 2017 No. 5 virgin consolidation ordinance. In response, they found that there were physicalchemical changes to color (20\%), turbidity (20\%), total hardness $(20 \%)$, chlorides (60\%), and ammonia ( $80 \%)$, as well as $100 \%$ microbiological contamination in the collected samples, being outside the maximum values allowed by the current ordinance, showing that the water sources are unsuitable for human consumption. Thus, the implementation of urgent measures needs to be carried out, in addition to improvements in basic sanitation in the region, in order to reduce or eliminate contaminants that may be present in the sources.
\end{abstract}

Keywords: Potable water; Waterborne diseases; Public health

Topic: Engenharia Sanitária

Reviewed anonymously in the process of blind peer.
Received: 04/02/2021

Approved: 24/02/2021
Jéssica Bezerra Maciel (iD)

Universidade Estadual do Ceará, Brasil http://lattes.cnpq.br/6316728722053585 http://orcid.org/0000-0002-8626-1257 jess-live@hotmail.com

Hudson Pimentel Costa (D)

Universidade da Integração Internacional da Lusofonia Afro-Brasileira, Brasil

http://lattes.cnpq.br/1075491623486578

http://orcid.org/0000-0002-9973-6100

hpimentelcostaunilab@gmail.com

\section{Danielle Rabelo Costa (iD)}

Centro Universitário Católica de Quixadá, Brasil http://lattes.cnpq.br/1571438061743046 http://orcid.org/0000-0002-8861-3885 daniellerabelo@unicatolicaquixada.edu.br

\begin{abstract}
Sérgio Horta Mattos (iD)
Centro Universitário Católica de Quixadá, Brasil http://lattes.cnpq.br/1564475788092552 http://orcid.org/0000-0001-8949-952X sergiohorta@unicatolicaquixada.edu.br

Francisco Glauber Peixoto Ferreira (i)

Universidade da Integração Internacional da Lusofonia Afro-Brasileira, Brasil http://lattes.cnpq.br/6898728780485440 http://orcid.org/0000-0002-3980-7253 glauber@hotmail.com
\end{abstract}

Olienaide Ribeiro de Oliveira Pinto (iD) Universidade da Integração Internacional da Lusofonia Afro-Brasileira, Brasil http://lattes.cnpq.br/8216617581480616 http://orcid.org/0000-0002-8333-3665 agron.olienaide@gmail.com

\author{
Lívia Paulia Dias Ribeiro (iD \\ Universidade da Integração Internacional da \\ Lusofonia Afro-Brasileira, Brasil \\ http://lattes.cnpq.br/3365997133213788 \\ http://orcid.org/0000-0003-3067-1908 \\ liviapaulia@unilab.edu.br
}

\section{Juan Carlos Alvarado Alcócer (iD)}

Universidade da Integração Internacional da

Lusofonia Afro-Brasileira, Brasil

http://lattes.cnpq.br/8172187725052094

http://orcid.org/0000-0002-6641-1617

jcalcocer@unilab.edu.br

\section{Referencing this:}

MACIEL, J. B.; COSTA, H. P.; COSTA, D. R.; MATTOS, S. H.; FERREIRA, F. G. P.; PINTO, O. R. O.; RIBEIRO, L. P. D.; ALCÓCER, J. C. A.. Qualidade da água consumida por uma comunidade rural na região do Sertão Central, Ceará. Revista Ibero Americana de Ciências Ambientais, v.12, n.2, p.317-327, 2021. DOI: http://doi.org/10.6008/CBPC21796858.2021 .002 .0029

DOI: 10.6008/CBPC2179-6858.2021.002.0029 


\section{INTRODUÇÃO}

A água é um bem inorgânico mais consumido pelos seres humanos, mais do que qualquer outra substância. É um recurso natural fundamental à vida e indispensável para a todos os seres vivos, capaz de suprir suas necessidades alimentares e também a sua saúde (MARTINS et al., 2016).

O Brasil apresenta a maior disponibilidade de água no mundo, porém, este recurso não está distribuído de forma uniforme e adequado para o consumo humano, a água padrão para o consumo humano é a potável e que se enquadra em parâmetros químicos, físicos e microbiológicos e que não oferece riscos à saúde e pode ser ingerida independente de sua origem (CALOI et al., 2020).

A grande importância da qualidade desse elemento para os seres humanos é notável e clara, no entanto, a sua disponibilidade vem se tornado cada vez mais difícil. O comprometimento da qualidade da água para fins de consumo humano é decorrente de poluição causada por diferentes fontes, tais como efluentes domésticos, efluentes industriais e deflúvio superficial urbano e agrícola. Estudos apontam que aproximadamente 1,5 bilhão de pessoas não têm acesso à água de boa qualidade, o que as leva a suprirem suas necessidades através de águas consideradas não potáveis, entretanto esses tipos de água tendem a oferecer riscos à saúde de seus consumidores podendo até a levar morte.

Tendo em vista essa problemática, a busca de novas tecnologias para o tratamento hídrico vem crescendo nos últimos anos assim, estudos de diversas áreas são realizados com o intuito de desenvolver meios que possam ajudar na melhoria da água de consumo humano.

Um dos meios mais utilizados no tratamento de água é a filtração. Essa prática é antiga tendo seus primeiros experimentos no início do século XIX, quando o escocês Jonh Gibb construiu o primeiro filtro de água do mundo utilizando como matéria prima a areia. Com o passar dos anos, novos filtros foram desenvolvidos com o intuito de inovar as formas de tratamento da água e os filtros derivados do carvão ativado constituem-se como umas das alternativas mais aceitas no meio cientificam. $\mathrm{O}$ carvão ativado pode utilizar vários tipos de matérias-primas diferentes chamadas de lignocelulose, como: madeira, casca de frutas, bagaço de cana de açúcar, palha de milho, dentre outros materiais que possuem uma quantidade de carbono relativamente alta. Esses tipos de matéria-prima tendem a ser aceitos no meio cientifico, pois são elementos, em sua maioria, biossustentáveis.

Fernandes et al. (2015) realizou estudos com a capacidade de filtração de águas do carvão ativado produzido com o endocarpo de coco e relatou que esse produto apresentou eficiência em reduzir a quantidade de matéria orgânica da água. No trabalho de alguns autores de 2005, eles utilizaram ossos bovinos para a produção de carvão ativo e observou a remoção de alguns metais pesados como $\mathrm{Zn}, \mathrm{Cu}, \mathrm{Cd}$, $\mathrm{Co}, \mathrm{Pb}$ e $\mathrm{Ni}$ em águas de efluentes de uma indústria minero-metalúrgica.

Estudos como esses revelam a necessidade de desenvolver ou de melhorar a qualidade das águas utilizadas para o consumo humano. Atualmente os parâmetros que estabelecem essa qualidade estão dispostos na Portaria de Consolidação no 5, de 28 de Setembro de 2017 do ministério da saúde (INSA, 2017).

Nesse contexto, o trabalho tem como objetivo desenvolver e avaliar a eficiência de filtros de 
tratamento de água usando carvão ativado de diferentes fontes de resíduo de biomassa, como casca da castanha do caju, descartes de madeira, entrecasca do coco e do colmo de bambu.

\section{MATERIAIS E MÉTODOS}

\section{Localização e caracterização da área estudada}

Trata-se de uma pesquisa do tipo observacional, de caráter transversal e abordagem qualitativa e quantitativa. O local de coleta pertence ao Distrito de Custódio, Município de Quixadá na região do Sertão Central no estado do Ceará, conforme as seguintes coordenadas: longitude de 3910'32.55"O e latitude de 459'06.79”'S. O clima é classificado como tropical semiárido, com precipitação pluviométrica semestral do atual ano de $776,4 \mathrm{~mm}$ e temperatura com variação de 20 a 30C (INSA, 1998; FUNCEME, 2018).

\section{Definição dos pontos de amostragem}

A avaliação da qualidade da água foi realizada em quatro poços semiartesianos denominados como poço 1 (P1), poço 2 (P2), poço 3 (P3) e poço 4 (P4) e um reservatório (açude). Conforme descrito, o P1, P2 e P3 estão distribuídos em diferentes localidades, porém o P4 pertence a uma creche, onde a água dessa fonte, em períodos de cheia, não é distribuída a população. Já com relação ao açude, o compartilhamento ocorre a partir de uma bomba autoaspirante do tipo injetora, na qual conduz a água pelo encanamento para outro reservatório, com destino as residências como exposto na Figura 1.

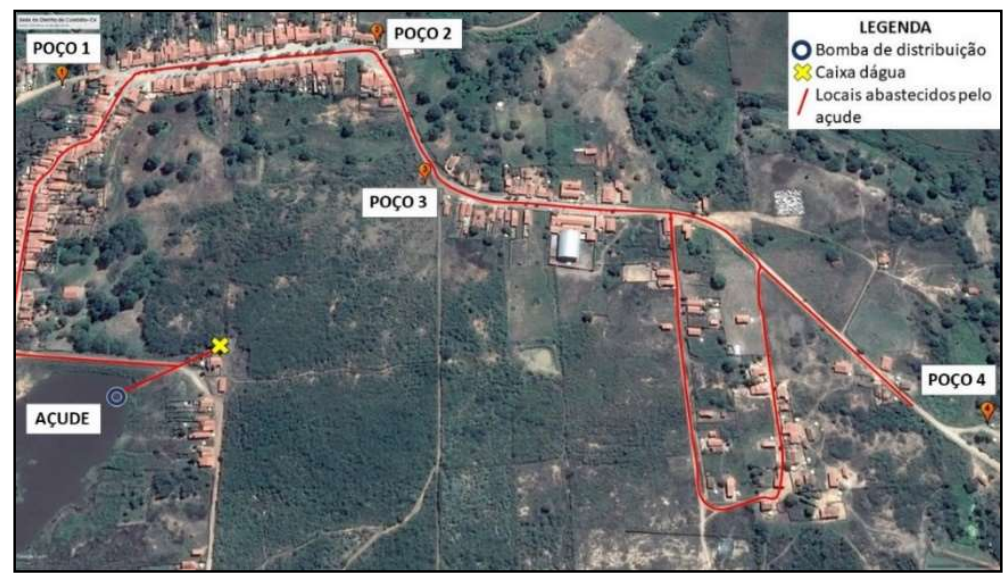

Figura 1: Localização das fontes alternativas de abastecimento da Sede do Distrito de Custódio e distribuição da água do açude. Fonte: Google Earth Pro (2017).

Optou-se por essas cinco fontes de abastecimento em razão pela disponibilidade e proximidade dos usuários. Com isso, a localização dos outros poços e seu alcance reduzido às demais residências limitaram a ampliação do estudo para todo o distrito. Contudo, a amostragem propiciou o levantamento de uma análise em que se pode correlacionar a representação dos dados em uma relação à estimativa aproximada de todo o território.

\section{Coleta e acondicionamento das amostras}

Nessa etapa foram realizadas duas visitas para coleta das amostras durante os meses de agosto e 
setembro de 2018, de modo a se programar conforme o período de início da estiagem na região. No entanto, apesar da qualidade da água sofrer variações devido à sazonalidade, no momento de escolha das amostras pode-se realizar uma avaliação preliminar.

Todos os procedimentos de higienização dos recipientes, coleta, e acondicionamento das amostras seguiram as recomendações do Manual Prático de Análise de Água da Fundação Nacional de Saúde (FUNASA, 2013). Além disso, os pesquisadores foram submetidos a treinamento prévio quanto às técnicas específicas, boas práticas de laboratório e manuseio de instrumentais de análise.

Em continuidade, as amostras físico-químicas foram coletas em recipientes de plásticos estéreis com tampa vedadora e capacidade para 1 litro. Dessa forma, todos os poços estavam equipados com torneiras do tipo metálicos, tornando-se necessário o processo de desinfecção com álcool a 70\%. Ao manuseio, desprezou-se de forma corrente a agua por um tempo protocolado de 2 minutos antes da coleta propriamente dita. No que tange ao açude, improvisou-se um instrumento composto por um barbante e recipiente plástico para obtenção da amostra, com localização próxima a bomba de distribuição.

Por último, as amostras microbiológicas foram coletadas em sacos plásticos Whirl-pak $100 \mathrm{~mL}$, com os mesmos protocolos de desinfecção citado anteriormente, porém, para a coleta no açude o saco plástico não foi submergido, sendo então coletada superficialmente.

\section{Análises laboratoriais}

Os parâmetros físico-químicos avaliados e os métodos utilizados nas análises laboratoriais das amostras estão descritos na Tabela 1. Todos foram determinados no Laboratório de Controle de Qualidade Físico Químico do Centro Universitário Católica do município de Quixadá (UNICATÓLICA).

Tabela 1: Parâmetros Físico-Químicos avaliados e métodos aplicados a amostra de água coletada do Munícipio de Custódio, Quixadá, Ceará, Brasil.

\begin{tabular}{|c|c|}
\hline Parâmetros & Métodos \\
\hline Odor & Sensorial \\
\hline Cor & Espectrofotometria, utilizando o aparelho HANNA - modelo DR/2013 \\
\hline $\begin{array}{l}\text { Ferro total e dissolvido } \\
\text { Sulfato } \\
\text { Amônia }\end{array}$ & $\begin{array}{l}\text { Espectrofotometria, utilizando o aparelho de espectofotômetro da marca Quimis mod. } \\
\text { Q7980RM }\end{array}$ \\
\hline Turbidez & Turbidímetrico, através o turbidímetro portátil marca Quimis modelo Q279P \\
\hline Potencial hidrogeniônico (pH) & Potenciometria, utilizando o aparelho da marca Quimis modelo Q400AS \\
\hline $\begin{array}{l}\text { Condutividade } \\
\text { Sólidos totais dissolvidos }\end{array}$ & $\begin{array}{l}\text { Condutimetria, utilizando o aparelho condutivímetro micro processado da marca Quimis } \\
\text { modelo Q485M }\end{array}$ \\
\hline Sódio e Potássio & Aparelho fotômetro de chama da marca Quimis modelo Q398M2 \\
\hline Alcalinidade & Titulometria com ácido clorídrico \\
\hline Cloretos & Titulometria com nitrato de prata \\
\hline $\begin{array}{l}\text { Dureza total, } \\
\text { magnesiana }\end{array}$ & Titulometria com EDTA \\
\hline
\end{tabular}

A avaliação das análises microbiológicas possui natureza qualitativa, e foi determinada a partir da utilização do substrato cromogênico para um possível resultado confirmativo da presença ou ausência de coliformes totais e/ou coliformes fecais. As amostras após coletadas permaneceram na estufa por um período de 24 horas a 35 ํㅡ, ocorrendo o desenvolvimento de coloração amarela em caso de positividade para coliformes totais, e a observação de fluorescência em caso de coliformes fecais, quando expostos a luz 
ultravioleta (UV) em $365 \mathrm{~nm}$.

Para a interpretação dos resultados foram considerados os limites expostos na Portaria de consolidação no5 de 2017 no anexo XX, que estabelece os parâmetros de potabilidade para águas destinadas ao consumo humano. A análise estatística foi realizada a partir de uma avaliação direta de quantidades, porcentagens e de tabelas utilizando o programa EXCEL $®$.

\section{RESULTADOS E DISCUSSÃO}

De acordo com os dados obtidos, foram evidenciadas alterações significativas nas amostras em comparação ao valor máximo permitido (VMP) pela portaria vigente nos parâmetros de cor, turbidez, dureza total, cloretos e amônia. Os demais parâmetros físico-químicos avaliados encontram-se dentro dos valores determinados, como exposto na Tabela 2.

Tabela 2: Resultado geral das análises físico-químicas.

\begin{tabular}{|c|c|c|c|c|c|c|c|}
\hline Parâmetro & Poço 1 (P1) & Poço 2 (P2) & Poço 3 (P3) & Poço 4 (P4) & Açude & V.M.P. & Unidades \\
\hline Turbidez & 1,56 & 2,96 & 1,61 & 1,43 & 5,45 & 5 & UT \\
\hline Cor & 4 & 13 & 6 & 7 & 110 & 15 & $\mathrm{UH}$ \\
\hline Odor & $\begin{array}{l}\text { Não } \\
\text { objetável }\end{array}$ & $\begin{array}{l}\text { Não } \\
\text { Objetável }\end{array}$ & $\begin{array}{l}\text { Não } \\
\text { Objetável }\end{array}$ & $\begin{array}{l}\text { Não } \\
\text { Objetável }\end{array}$ & $\begin{array}{l}\text { Não } \\
\text { Objetável }\end{array}$ & $\begin{array}{l}\text { Não } \\
\text { objetável }\end{array}$ & - \\
\hline $\mathrm{pH}$ & 7,70 & 7,96 & 7,77 & 7,55 & 7,40 & 6,0 a 9,5 & - \\
\hline Hidróxidos & 0 & 0 & 0 & 0 & 0 & NE & $\mathrm{mg} \mathrm{OH} / \mathrm{L}$ \\
\hline Carbonatos & 0 & 0 & 0 & 0 & 0 & NE & $\mathrm{mg} \mathrm{CO} 3 / \mathrm{L}$ \\
\hline Bicarbonatos & 290 & 466 & 390 & 480 & 152 & NE & $\begin{array}{ll}\mathrm{mg} & \mathrm{CaCO}_{3} \\
/ \mathrm{L} & \end{array}$ \\
\hline Dureza Total & 392 & 446 & 392 & 586 & 200 & 500 & $\begin{array}{ll}\mathrm{mg} & \mathrm{CaCO}_{3} \\
/ \mathrm{L} & \end{array}$ \\
\hline Cálcio & 52,8 & 40,0 & 39,2 & 18,4 & 40,0 & NE & $\mathrm{mg} \mathrm{Ca} \mathrm{/} \mathrm{L}$ \\
\hline Magnésio & 0,062 & 0,071 & 0,083 & 0,129 & 0,024 & NE & $\mathrm{mg} / \mathrm{L}$ \\
\hline Condutividade & 1153 & 1620 & 1046 & 1470 & 673 & NE & $\mu \mathrm{s} / \mathrm{cm}$ \\
\hline Cloretos & 330,6 & 482,6 & 199,3 & 405,6 & 158,9 & 250 & $\mathrm{mg} \mathrm{Cl}^{-} / \mathrm{L}$ \\
\hline Sulfato & 42,8 & 86,2 & 102,1 & 144,2 & 50,0 & 250 & $\mathrm{mg} \mathrm{SO}_{4} 2-/ \mathrm{L}$ \\
\hline Ferro & 0,03 & 0,06 & 0,019 & 0,03 & 0,006 & 0,3 & $\mathrm{mg} \mathrm{Fe} / \mathrm{L}$ \\
\hline Sódio & 139,7 & 194,2 & 130,1 & 165,5 & 92,1 & 200 & $\mathrm{mg} \mathrm{Na} / \mathrm{L}$ \\
\hline Potássio & 7,0 & 14,3 & 16,5 & 12,4 & 17,2 & $\mathrm{NE}$ & $\mathrm{mg} \mathrm{K} / \mathrm{L}$ \\
\hline Amônia & 5,8 & 6,3 & 2,8 & 5,9 & 0,8 & 1,5 & $\begin{array}{ll}\mathrm{mg} & \mathrm{N}-\mathrm{NH}_{3} \\
/ \mathrm{L} & \end{array}$ \\
\hline Sólidos Totais & 596 & 833 & 536 & 767 & 341 & 1000 & mg STD / L \\
\hline
\end{tabular}

*V.M.P. - Valor Máximo Permitido.

*NE - Não estipulado pela Portaria de consolidação n5/2017 anexo XX - Ministério da Saúde.

Dentre os parâmetros avaliados, a turbidez e a cor são indícios da presença de sólido dissolvidos, como matérias orgânicas ou inorgânicas, como também o ferro em grandes quantidades. Alterações nesses fatores (Figuras 2 e 3 ) podem ser originadas devido ao escoamento superficial que conduzem essas partículas para a água pela erosão das margens da fonte ou ainda por resíduos domésticos (GANDRA, 2012).

Corroborando com os resultados encontrados, Koch et al. (2017) analisaram 8 fontes de águas superficiais para consumo humano em um município do Rio Grande do Sul, onde foram evidenciadas alterações em todas as suas amostras, contendo valores superiores para turbidez e cor, não atendendo ao critério de potabilidade quanto a esses parâmetros. Resolução similar foi alcançada por Freitas (2017), que também realizou análise de fontes superficiais de abastecimento, onde foram verificados 13 pontos de amostragem, sendo que 6 apresentaram elevação de turbidez, e 11 estavam com o parâmetro cor acima do 
determinado.

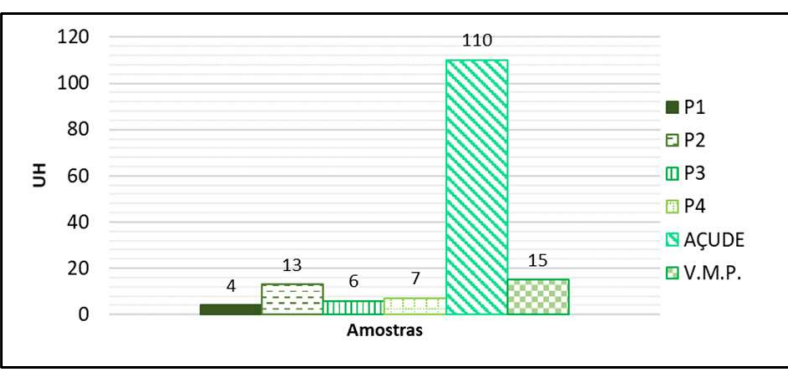

Figura 2: Valores obtidos nas análises de cor da amostra de água.

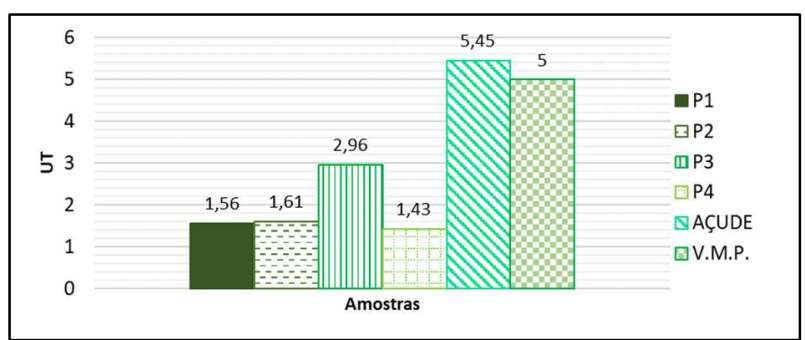

Figura 3: Valores obtidos nas análises de turbidez das amostras.

Quanto ao parâmetro da cor da água, este possui grande valor estético, uma vez que causa considerável impacto visual e de sabor, chama atenção referente ao seu aspecto, além de ocasionar manchas em tecidos durante o processo de lavagem, e acumular-se em tubulações devido à presença dos sólidos dissolvidos. Já a turbidez é considerada um indicador sanitário, refletindo a situação da água utilizada, sendo útil para a vigilância, sua elevação pode contribuir para a multiplicação de microrganismos, já que de uma certa forma, atrapalha a ação dos agentes de desinfecção, impedindo seu contato de superfície devido a proteção como fator de resistência, se torna também um limitante ambiental, na medida em que que sua elevação diminui o recebimento de luz suficiente para a realização de fotossíntese (MARTINS et al., 2016).

As águas de todos os poços apresentaram normalidade para cor e turbidez. Diante dos critérios, INSA (2007) expõe que águas subterrâneas como a de poços costumam ter valores de turbidez e cor normais, devido a características predominantes de filtragem natural pelo solo ou rochas dessas fontes. Em estudo feito nas águas subterrâneas provenientes de poços na Zona Urbana de Pombal-PB, também em períodos de estiagem, os três poços analisados apresentaram normalidade para cor e turbidez, confirmando a afirmativa de que possivelmente a filtragem do solo favorece a normalização desses parâmetros (CRISPIM et al., 2017), achados estes com similaridade ao presente estudo.

No caso da dureza total, sua elevação pode ocorrer pelo excesso de sais de cálcio e magnésio dissolvidos, visto que, a água direcionada para consumo é rica nesse tipo de material que ao se dissolverem liberam íons, esse processo pode ocorrer por meio da passagem da água pelo solo ou encanamento (FERNANDES et al., 2015). Este fato pode ser a causa da alteração presente na amostra P4 (Figura 4), de modo que a água desse poço percorre o encanamento até que chegue ao reservatório da creche, mencionada ao longo do texto, onde será então direcionada para consumo, diferentemente dos outros poços que não possuem encanamento.

A avaliação feita por Bagatini et al. (2017) determinou que, em 10 poços na cidade de Roca Sales no Vale do Taquari no Rio Grande do Sul, todas as amostras estavam com valores dentro do determinado pela portaria vigente. Em outro estudo feito por Casali (2008), contemplou 29 escolas rurais que fazem a utilização de fontes subterrâneas de abastecimentos, e nenhuma apresentou alterações no parâmetro de dureza total. Deste modo, a ocorrência de alteração somente em uma das fontes, revela que essas fontes subterrâneas apresentam parâmetros de normalidades. 
Assim, águas consideradas como duras dificultam o processo de lavagem de roupas, pois os íons Cálcio $\left(\mathrm{Ca}^{2+}\right)$ e Magnésio $\left(\mathrm{Mg}^{2+}\right)$ reagem com o sabão originando sais insolúveis, de forma a prejudicar a eficiência dessa atividade e proporcionar um gasto maior de produtos adstringentes. Ademais, é capaz ainda de causar formação de crostas insolúveis em ambientes higienizados com tal mistura. Quando submetida à ebulição, pode ocorrer a precipitação desses sais e redução de dureza na água. Esse fator pode ainda estar associado a alterações de potencial hidrogeniônico $(\mathrm{pH})$ e alcalinidade, porém, as amostras analisadas encontram-se dentro dos padrões (SOARES, 2016).

A presença de valores de cloretos elevada (Figura 5) podem ser percebidas pelo sabor mais salgado na água, além de causar efeito purgativo, levando a alterações no fluxo regular intestinal (ALVES, 2017). Situação está vinculada ao consumo sem tratamento ou purificação adequada, que indica acima de tudo a presença de citocinas ou microrganismos presentes no trato digestivo.

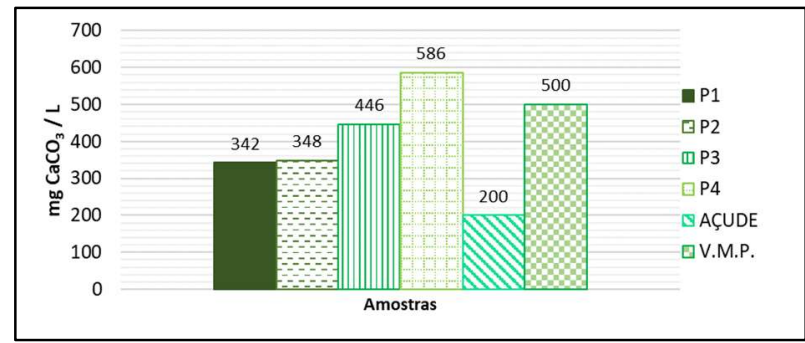

Figura 4: Valores obtidos do parâmetro dureza total conforme amostras.

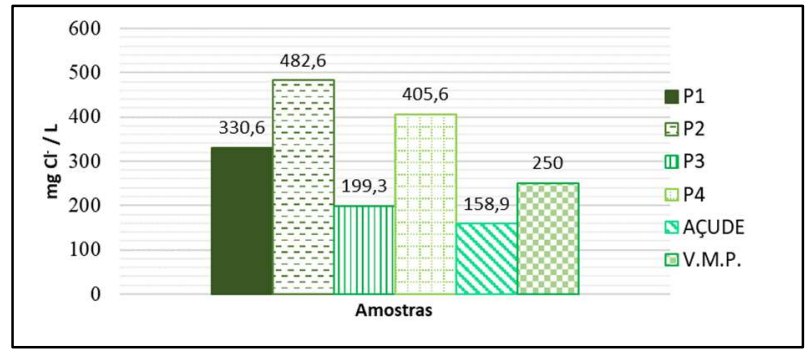

Figura 5: Valores obtidos do parâmetro cloretos conforme amostras.

Em contrapartida aos resultados obtidos, Souza et al. (2018) ao analisarem águas provenientes de fontes alternativas de captação na cidade de Astolfo Dutra, Minas Gerais, relataram que na avaliação de 9 poços semiartesianos houve a presença de cloretos. Resultados semelhantes foram encontrados em análise realizada na Capital Fortaleza, no Estado do Ceará por Bezerra et al. (2018), em águas subterrâneas originadas de poços, no qual os valores de cloretos estavam elevados apenas em 1,7\% das amostras.

Entretanto, Saling (2017) esclarece que a elevação de cloretos pode ter conexão com a contaminação de esgotos domésticos, aterros sanitários ou lixões em um corpo hídrico, fato presente na cidade desse estudo, pois o mesmo, além de possuir ausência de atividade de rede pública de abastecimento de água para as residências, não dispõe de esgotamento sanitário, o que implica em $60 \%$ das amostras apresentarem esse excesso, já que a comunidade faz a utilização de fossas sépticas, que podem fornecer material contaminante, afetando a qualidade dos lençóis freáticos.

Segundo Instituto Brasileiro de Geografia e Estatística - IBGE (2010), cerca de 52,7\% da população de Quixadá possui esgotamento sanitário adequado. Entretanto a outra parcela da população que não possui, faz uso de outras alternativas quanto aos dejetos, como a utilização de fossas, podendo ocasionar a contaminação das fontes que são utilizadas para aquisição desse recurso natural.

Para Alves (2017) os métodos de tratamento geralmente utilizados não promovem a retirada do excesso de cloreto na água, pois métodos mais específicos como a desmineralização ou evaporação podem promover essa remoção, e reduzir seus impactos negativos. Do mesmo modo, a presença de amônia em 
fontes de abastecimento observada na Figura 6, podem ser um indicativo de contaminação recente por meio de esgoto bruto, efluentes industriais, ou uso de fertilizantes. Sua constituição ocorre a partir da decomposição de matéria orgânica, sendo considerada uma fonte potencial de nitrato, pois devido a ação de bactérias quimioautotróficas a amônia é rapidamente convertida em nitrato (CORREIA et al., 2015).

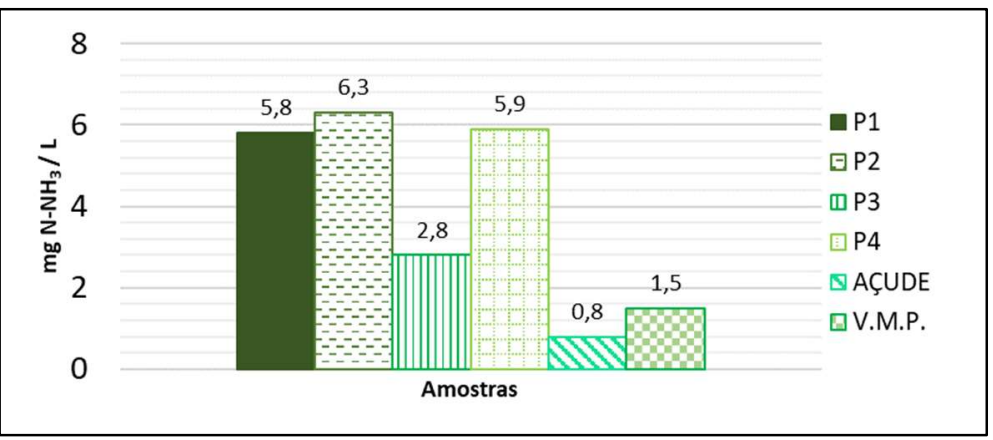

Figura 6: Valores obtidos do parâmetro amônia conforme amostras do estudo.

Em contestação, uma análise realizada em poços na Cidade de Apodi no Rio Grande do Norte por Tavares et al. (2012) revelaram que todas as amostras exibiram normalidade para presença de amônia. Por outro lado, resultados semelhantes foram obtidos por Scorsafava et al. (2010) ao analisarem 1.356 poços no Estado de São Paulo, no qual concluíram que apenas 1,1\% das amostras possuíam amônia acima do recomendado. Estes resultados podem ter sido ocasionados devido a oxidação rápida de amônia em nitrito, desta forma, a presença de amônia nas amostras do distrito em estudo pode ser indicativa de contaminação recorrente, originada pela presença das fossas sépticas nas proximidades das fontes.

Os resultados da análise microbiológica de todas as amostras (Figuras 7 e 8) evidenciaram 100\% de contaminação por coliformes totais e fecais (Tabela 3), sendo que a portaria vigente estabelece que em uma amostra de $100 \mathrm{~mL}$ de água o resultado obtido seja negativo/ausente para coliformes totais e fecais. Essas contaminações, provavelmente podem estar relacionadas à proximidade de fossas sépticas aos poços, aliado ao fato de também não haver um sistema de impermeabilização dos mesmos, aumentando ainda mais a ocorrência de contaminação.

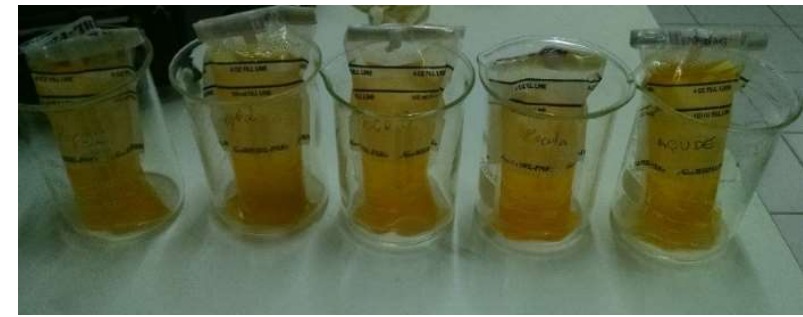

Figura 7: Teste microbiológico confirmando a presença de coliformes totais nas amostras.

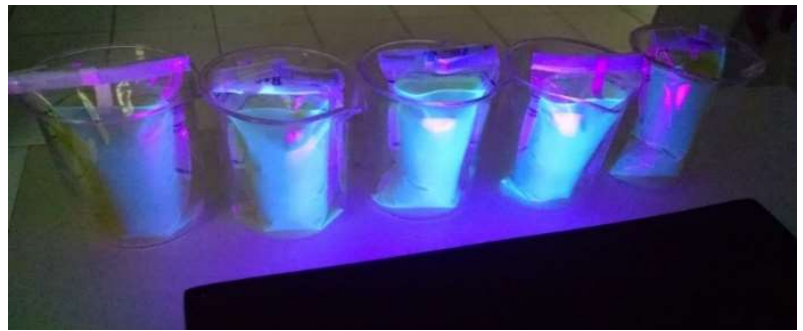

Figura 8: Teste microbiológico confirmando a presença de coliformes fecais nas amostras.

Nenhum processo de desinfecção foi realizado nos poços, uma vez que, a Portaria de consolidação no5 de 09/2017 do Ministério da Saúde destaca que "Toda água para consumo humano, fornecida coletivamente, deverá passar por processo de desinfecção ou cloração". Este último, muito aplicado nesse tipo de fonte, inativará microrganismos e oxidará matéria orgânica pela ação de produtos químicos que tem como base o cloro, reduzindo as chances de a fonte de abastecimento promover contaminação aos 
consumidores (INSA, 2017; FUNASA, 2014).

Tabela 3: Resultados das análises microbiológicas das amostras de agua dos poços.

\begin{tabular}{|c|c|c|c|c|c|c|}
\hline Parâmetros microbiológicos & P1 & P2 & P3 & P4 (Creche) & Açude & Portaria de consolidação no5/2017 \\
\hline Coliformes totais & Presente & Presente & Presente & Presente & Presente & Ausência em 100 mL \\
\hline Coliformes fecais & Presente & Presente & Presente & Presente & Presente & Ausência em 100 mL \\
\hline
\end{tabular}

Em concordância com os resultados atingidos, um estudo feito na Cidade de Curitiba-Paraná a partir da análise da água de 10 poços, determinou que em todas as amostras foram comprovadas a presença de coliformes totais, dentre essas, em 4 amostras (40\%) foram observadas a presença de Escherichia coli, um tipo de bactéria categorizada como fecal (SILVA et al., 2005).

Essas bactérias podem ser encontradas nas fezes de seres humanos, bem como em animais considerados como de sangue quente; assim, sua presença na água é um indicativo de contaminação fecal, sendo então classificada como imprópria para consumo, já que esses tipos de bactérias, em especial a E. coli, são causadoras de patologias gastrointestinais (BRUM et al., 2016). No caso das águas superficiais, sua contaminação microbiológica pode ter ocorrido em decorrência da presença de dejetos de animais que frequentam o local, promovendo a partir do escoamento superficial, visto que, as amostras foram coletadas próximas a bomba de abastecimento localizada nas proximidades da margem.

Análise semelhante realizada por Neves et al. (2016) em 18 amostras coletas em diferentes pontos de 3 açudes no distrito de Morrinhos no Estado do Ceará, evidenciou a presença de 100\% de contaminação por coliformes totais e fecais nas amostras analisadas. Em concordância Andrade (2015) realizou testes em águas superficiais na cidade de Coremas e Pombal-Paraíba, nos quais, foi atestada a presença de coliformes totais e fecais nas amostras analisadas.

Além disso, de acordo com a Portaria de consolidação no5 de 09/2017, “As águas provenientes de manancial superficial devem ser submetidas a processo de filtração". Esse processo permite a passagem do fluido e impede que materiais em suspensão ou até microrganismos permaneçam na água dependendo do tipo de filtro utilizado. Os filtros de membrana vêm sendo muito empregados para o tratamento de água, já que esse método tem a capacidade de promover alta remoção de microrganismos na água (INSA, 2017; GHIGGI, 2011).

O método de desinfecção solar da água (SODIS) também vem apresentando resultados significativos na redução de microrganismos, em razão de ser um procedimento barato e simples de se realizar, obtendose como principal resultado a desinfecção pela radiação solar, processo este muito aplicado em localidades com infraestrutura e recursos financeiros reduzidos (GOLIN, 2018).

\section{CONCLUSÕES}

As amostras analisadas não estão de acordo com os parâmetros exigidos pela portaria vigente do Ministério da Saúde, voltados aos marcadores físico, químicos e principalmente os microbiológicos, classificando então, a água consumida no distrito como imprópria para consumo humano.

Diante do quadro microbiológico das fontes analisadas, a elaboração e disponibilização da cartilha 
de orientação sobre métodos caseiros de desinfecção da água trarão grandes benefícios, possibilitando a redução de contaminação, para que a água possa ser consumida com segurança.

A disponibilização dos resultados das análises as autoridades promoverão um alerta sobre a necessidade de intervenção por parte dos mesmos a fim de reduzir a periodicidade de casos de DVH. Como o estudo foi categorizado como preliminar, aconselha-se amplifica-lo para todo o distrito, como também colocar em prática a realização de um monitoramento periódico e avaliação dessas fontes como recomenda a portaria vigente, garantindo então seu consumo e a minimização de riscos que podem surgir para a saúde dos usuários dessas fontes.

\section{REFERÊNCIAS}

ALVES, I. T. F.. Estudo comparativo da qualidade da água do açude Epitácio Pessoa pré e pós-transposição do rio São Francisco. Monografia (Bacharelado em Bioquímica Industrial) - Universidade Estadual da Paraíba, Campina Grande, 2017.

ANDRADE, S. O.. Análise espacial da qualidade microbiológica das águas do rio Piancó no trecho CoremasPombal-PB. Revista Verde, v.10, n.2, p.157-161, 2015.

BAGATINI, M.; BONZANINI, V. OLIVEIRA, E. C.. Análise da qualidade da água em poços artesianos na região de Roca Sales, Vale do Taquari. Revista Caderno Pedagógico, v.14, n.1, p.84-91, 2017

BEZERRA, A. D. A.; ROCHA, J. C.; NOGUEIRA, E. R.; SOUSA, D. M. L.; ARAÚJO, F. G. D. M.; BRNDÃO, M. G. A.; PANTOJA, L. D. M.. Análise situacional da qualidade de água subterrânea oriunda de poços da Região Metropolitana de Fortaleza, Ceará, Brasil. Acta Biomedica Brasiliensia, Fortaleza, v.9, n.1, p.94-104, 2018.

BRUM, B. R.; OLIVEIRA, N. R.; REIS, H. C. O.; LIMA, Z. M.; MORAIS, E. B.. Qualidade das águas de poços rasos em área com déficit de saneamento básico em Cuiabá, MT: Avaliação microbiológica, físico química e fatores de risco à saúde. Holos, v.32, n.2, p.179-188, 2016.

CASALI, C. A.. Qualidade da água para consumo humano ofertada em escolas e comunidades rurais da região central do Rio Grande do Sul. Dissertação (Mestrado em Ciência do Solo) - Universidade Federal de Santa Maria, Santa Maria, 2008.

CALOI, C. S. G.; GONÇALVES, E. A.; FIGUEIREDO, A. C. B.; OLIVEIRA, J. R.; CAMPOS, A. S.; QUEIROZ, T. M.. Qualidade de águas consumidas por alunos indígenas em escola rural de Barra do Bugres/MT. Revisto Ibero-Americana de Ciências Ambientais, v.11, n.4, p.169-179, 2020. DOI: http://doi.org/10. 6008/CBPC2179-6858.2020.004.0015

CORREIA, L. J. H.; FERNANDES, A. J. D.; LÚCIO, M. M. L. M.; TOMAZ, J. K. O.; HONORATO, M.; M. B.; CARNEIRO, E. N.. Monitoramento da qualidade físico-química da água do estuário do Rio Paraíba - Cabedelo, PB. Revista Principal, v.1, n.27, p.47-54, 2015. DOI: http://dx.doi.org/10.18265/1517-03062015v1n27p47-54

CRISPIM, D. L.; OLIVEIRA, A. M. B. M.; CHAVES, A. D. C. G.;
FERNANDES, N. L.; BARRETO, N. M. B.; MACHADO, A. C.; ROCHA, G. P.. Estudo comparativo entre metodologias utilizadas para determinação de dureza total em matrizes aquosas. Tchê Química, v.12, n.24, p.91-95, 2015.

FREITAS, M. O.. Avaliação da qualidade geoquímica ambiental da água superficial do rio Jequitinhonha sob impacto de atividade garimpeira. Dissertação (Mestrado) Universidade Federal dos Vales do Jequitinhonha e Mucuri, Teófilo Otoni, 2017.

FUNASA. Ministério da Saúde. Coordenação de Comunicação Social. Fundação Nacional de Saúde. Manual prático de análise de água. Brasília: Ministério da Saúde, 2013.

FUNASA. Ministério da Saúde. Coordenação de Comunicação Social. Ministério da Saúde. Departamento de Saúde Ambiental. Fundação Nacional de Saúde. Manual de cloração de água em pequenas comunidades: utilizando o clorador simplificado desenvolvido pela Funasa. Brasília: Ministério da Saúde, 2014

FUNCEME. Governo do Estado do Ceará. Tipos Climáticos. Fortaleza: FUCEME, 2018.

GANDRA, M. F. A.. Qualidade de águas e sedimentos em rios de pequena ordem drenando Eucalyptus ssp e cerrado antropizado no Alto e Médio São Francisco e Alto Jequitinhonha, MG. Dissertação (Mestrado em Engenharia Industrial) - Centro Universitário do Leste de Minas Gerais, Coronel Fabriciano, 2012

GHIGGI, F. F.. Tratamento de águas para consumo doméstico com membranas de ultrafiltração. Monografia (Bacharelado em Engenharia Química) - Universidade Federal do Rio Grande do Sul, Porto Alegre, 2011.

GOLIN, N.. Avaliação da eficiência do método SODIS na desinfecção da água para consumo humano em Pelotas, RS. Monografia (Bacharelado em Engenharia ambiental e sanitária) - Universidade Federal de Pelotas, Pelotas, 2018.

IBGE. Instituto Brasileiro de Geografia e Estatística. Quixadá: Panorama. Fortaleza: IBGE, 2010.

INSA. Instituto Nacional do Semiárido. Ministério de Minas e Energia. Secretaria de Minas e Metalurgia. Programa de recenseamento de fontes de abastecimento por água subterrânea no Estado do Ceará: diagnóstico do município 
de Quixadá. Fortaleza: Ministério de Minas e Energia, 1998.

INSA. Instituto Nacional do Semiárido. Ministério do Meio Ambiente. Associação brasileira de águas subterrâneas.

Águas subterrâneas: um recurso a ser conhecido e protegido. Brasília: Ministério do Meio Ambiente, 2007.

INSA. Instituto Nacional do Semiárido. Ministério do Meio Ambiente. Portaria de Consolidação n. 5, de 28 de setembro de 2017. Brasília: Consolidação das normas sobre as ações e os serviços de saúde do Sistema Único de Saúde, 2017.

KOCH, F. F.; KAUFFMANN, C.; BICA, J. B.; ADAMI, F. S.; STEVENS, J. F.; ECKHARD, C. L.; MARMIT, G. L.; OLIVEIRA, E. C.. Análise de Água Superficial para consumo humano em um município do Rio Grande do Sul. Caderno Pedagógico, v.14, n.1, p.36-50, 2017.

MARTINS, V. J.; OZAKI, S. K.. A análise dos parâmetros de potabilidade da água de escolas públicas de RondonópolisMT. In: ENCONTRO NACIONAL DE ENSINO DE QUÍMICA ENEQ. Anais. Rondonópolis: UFMT, 2016.

NEVES, A. M.. Análise microbiológica da água de um açude localizado no município de Morrinhos - CE. Enciclopédia Biosfera, v.13, n.24, p.1100-1110, 2016.

SALING, C.; GRAFF, A.; OLIVEIRA, E. C.; BÖCKEL, W. J.. Avaliação da qualidade da água de poços rasos no município de Colinas, RS. Tecno-lógica, Santa Cruz do Sul, v.21, n.2, p.59-64, 2017.

SCORSAFAVA, M. A.; SOUZA, A.; STOFER, M.; NUNES, C. A.; MILANEZ, T. V.. Avaliação físico-química da qualidade de água de poços e minas destinada ao consumo humano. Revista do Instituto Adolfo Lutz, v.2, n.2, p.229-232, 2010.

SILVA, R. C. A.; ARAÚJO, T. M.. Consumo humano de água de manancial subterrâneo em áreas urbanas de Feira de Santana-BA. Revista Baiana de Saúde Pública, v.29, n.2, p.326-338, 2005.

SOARES, A. C. F.. Avaliação da qualidade da água tratada distribuída em Campina Grande. Monografia (Bacharelado em Química industrial) - Universidade do Estado do Pará, Belém, 2016.

SOUZA, W. B.; MELO, L. P.; LIMA, L. C. S.; SOUZA, D. C.; TEIXEIRA, T. T.. Mapeamento e avaliação da potabilidade de água proveniente de fontes alternativas de captação na cidade de Astolfo Dutra. Águas Subterrâneas: Seção Estudos de Caso e Notas Técnicas, v.32, n.3, p.1-7, 2018.

TAVARES, J. A.; OLIVEIRA, J. J. V.; COSTA, M. V. O.; LIMA, S. L. C.; LIMA, S. L. C.; LIMA, M. A. A.. Análise Físico-Química da Água dos poços IPE e IFRN: Campus Apodi. In: CONGRESSO NORTE E NORDESTE DE PESQUISA E INOVAÇÃO - CONNEPI,

7. Anais. Palmas: UFTO, 2012.

A CBPC - Companhia Brasileira de Produção Científica (CNPJ: 11.221.422/0001-03) detém os direitos materiais desta publicação. Os direitos referem-se à publicação do trabalho em qualquer parte do mundo, incluindo os direitos às renovações, expansões e disseminações da contribuição, bem como outros direitos subsidiários. Todos os trabalhos publicados eletronicamente poderão posteriormente ser publicados em coletâneas impressas sob coordenação da Sustenere Publishing, da Companhia Brasileira de Produção Científica e seus parceiros autorizados. Os (as) autores (as) preservam os direitos autorais, mas não têm permissão para a publicação da contribuição em outro meio, impresso ou digital, em português ou em tradução. 